\title{
TRAYECTORIAS LABORALES DE MIGRANTES CALIFICADOS RETORNADOS A LA CIUDAD DE CALI, COLOMBIA
}

\section{LABOR TRAJECTORIES OF THE QUALIFIED MIGRANTS RETURNED TO THE CITY OF CALI, COLOMBIA}

Rosa Emilia Bermúdez Rico*, Luisa Fernanda Zapata López**

Resumen: En este artículo se analizan las trayectorias laborales de migrantes calificados retornados a la ciudad de Cali, Colombia, entre 2010 y 2016, tras su experiencia migratoria en Estados Unidos o España y se establecen los principales rasgos y circunstancias que definen su inserción laboral en el retorno. Se acudió a un diseño de investigación cualitativa, entrevistando directamente a personas retornadas. Se contrasta el proceso de integración sociolaboral de las personas retornadas vinculadas al mercado laboral en calidad de asalariadas, con aquellas retornadas clasificadas como trabajadoras independientes, destacándose las diferencias en las posibilidades de aprovechar la experiencia migratoria.

Palabras claves: migración de retorno calificado; inserción laboral de retornados; trayectorias de emigrantes retornados.

* Profesora Investigadora del Departamento de Ciencias Sociales de la Universidad del Valle. Cali-Colombia, rosa.bermudez@correounivalle.edu.co

** Magíster en Sociología de la Universidad del Valle. Cali-Colombia, luisafernanda.zalo@gmail.com 
Abstract: In this article, we analyze the labor trajectories of qualified migrants returned to the city of Cali, Colombia, between 2010 and 2016, after their migration experience in the United States or Spain and establish the main features and circumstances that define their labor insertion in the return. To do this, a qualitative research design was used and in-depth interviews were conducted directly with returnees. This contrasts the process of socio-labor integration of returnees linked to the labor market as wage earners, with those returned classified as independent workers, highlighting differences in working conditions and in the possibilities of taking advantage of the migratory experience.

Key words: qualified return migration; labor insertion of returnees; trajectories of returned emigrants.

\section{INTRODUCCIÓN}

En las últimas décadas, diversos estudios han subrayado una mayor heterogeneidad en los flujos migratorios asociada con una mayor diversidad en los orígenes de los migrantes internacionales. También, se ha enfatizado en el incremento en la participación de las mujeres en los flujos migratorios, en una mayor diversidad en los motivos asociados con la migración y, de manera especial, se ha señalado la importancia que han adquirido los flujos de migrantes con alta calificación. Estos rasgos emergentes configuran la migración internacional como un fenómeno cada vez más diverso y complejo (Durand y Massey, 2003; Bermúdez, 2014, p. 259).

En el contexto de los flujos migratorios sur norte, el retorno a los países de origen ha adquirido una singular importancia dado que el retorno de inmigrantes procedentes de los países del norte global es superior comparado con periodos anteriores a la crisis económica y financiera internacional iniciada en el 2007. Este incremento de los flujos de retorno a los países de origen constituye un giro importante en la dinámica migratoria y un proceso altamente selectivo (Martínez, Cano y Soffia, 2014, p. 29). Prieto, Pellegrino y Koolhaas (2015) señalan que los flujos de retorno en cinco países en América Latina, presentan una intensidad distinta según el país de procedencia y una selectividad diferenciada de los retornados asociadas al país de procedencia y de origen. 
La migración de retorno constituye una fase inacabada y dinámica del proyecto migratorio, con múltiples aristas delineadas por factores subjetivos, circunstancias económicas y sociales tanto en el contexto de la sociedad receptora como de origen. Se han analizado tanto los determinantes como los motivos del retorno, el momento del ciclo migratorio en que ocurre, las formas de gestión de los recursos o capitales acumulados por los retornados y los procesos que acompañan el retornado a nivel familiar e institucional (Cassarino, 2008; Shramm, 2011; Nieto, 2012; Rivera, 2013; Valenzuela y Medina, 2015).

Algunos estudios comparativos sobre el retorno en América Latina, con base en el análisis de datos censales han establecido que las personas retornadas se ubican en condiciones laborales con mayores desventajas frente a personas sin experiencia migratoria y nivel de escolaridad similar. En el caso de Uruguay, se identifica que los retornados recientes, presentan tasas de desocupación altas y los retornados más antiguos presentan una mayor participación en empleos en condiciones de sobre-cualificación y por fuera del sistema de protección social; indicadores válidos, incluso, en retornados con nivel educativo superior (Koolhaas, 2015). En el caso de retornados calificados en contextos urbanos en México, aunque presentan altas tasas de participación en el mercado laboral, un porcentaje considerable presenta condiciones de trabajo en mayor desventaja, en comparación con mexicanos sin experiencia migratoria en áreas de ocupación similares. Se señala que 31 de cada 100 personas retornadas licenciadas, se ocupan como profesionales, mientras que 44 de cada 100 licenciados sin experiencia migratoria, tienen este estatus laboral (Ramírez y Lozano, 2015, p. 206).

Para el caso de Colombia, los emigrantes retornados enfrentan barreras y desventajas derivadas de un entorno económico, normativo e institucional hostil (Castro y Mejía, 2012; Prieto, 2015). Entre los factores que aumentan la exclusión en el mercado laboral se señala la alta edad promedio al retorno que afecta en mayor medida a las personas con baja calificación (Castro y Mejía, 2012); la exigencia de documentación que acredite experiencia y referencias laborales y la menor retribución salarial que se les ofrece con respecto al país de procedencia, generando insatisfacción y baja adaptación (Prieto, 2015).

En este artículo se examina la incidencia de la experiencia migratoria en los procesos de inserción laboral, en particular, se analizan las circunstancias en las que los retornados gestionan capitales y 
recursos acumulados. Se considera el estatus laboral de las personas retornadas y sus condiciones de trabajo. Con este propósito se analizan las trayectorias laborales de diez personas retornadas, de una muestra seleccionada con los siguientes criterios: hombres y mujeres, con once años y más de educación formal que emigraron desde Cali hacia Estados Unidos o España en los últimos veinte años y retornaron a la ciudad antes del 2015. El nivel de escolaridad alcanzado, así como la experiencia y especialización acumulada establecen el carácter de migración calificada de retorno ${ }^{1}$. En este estudio la definición de migración calificada abarca: "la posición ocupacional que se tiene en la estructura del empleo — tanto en el país de origen como en el de destino-, asociándola con el nivel de escolaridad o sustituyéndola por ésta" (Bermúdez, 2010, p. 136). Las personas entrevistas se contactaron mediante la estrategia de bola de nieve.

$\mathrm{El}$ artículo se estructura de la siguiente manera. En primer lugar, se discute la importancia conceptual del análisis de la migración calificada de retorno y se describen las perspectivas analíticas y metodológicas para el estudio de este flujo migratorio. En segundo lugar, se presentan y analizan las trayectorias laborales de las personas retornadas calificadas y se discute el significado que adquiere la experiencia migratoria en la inserción laboral. Para finalizar, se presentan algunas reflexiones de conjunto en torno a los principales hallazgos.

\section{LA MIGRACIÓN CALIFICADA DE RETORNO: PERSPECTIVAS ANALÍTICAS Y METODOLÓGICAS}

La migración de retorno constituye un proceso complejo, con múltiples efectos a nivel personal, familiar y con interdependencia en el entorno económico e institucional (Rivera, 2013). Se consideran los aportes del enfoque histórico-estructural y de redes sociales para abordar la migración de retorno como un evento multidimensional que requiere analizarse en función del proceso migratorio y de los factores macro y micro estructurales que lo definen (Durand y Massey, 2003).

1 Las cinco mujeres registran formación universitaria; una sin titulación. Los hombres registran formación: dos técnicos industriales, uno con secundaria completa y dos con formación universitaria. 
Castro y Mejía (2012, p. 19) establecen que el retorno se define como: "el regreso de un migrante internacional a su país de origen, con intención de restablecer su residencia, independiente de la duración de su estadía en el exterior y de la eventualidad de una re- emigración posterior". Esta definición trasciende la idea del retorno como un desplazamiento de ida y de regreso definitivo y considera la continuidad de la trayectoria migratoria, así como la importancia que tienen los vínculos y las redes sociales que articulan las sociedades receptoras y las de origen (Pedone, 2003; Hirai, 2013).

En este análisis consideramos sólo el retorno voluntario, como aquel que se presenta cuando "se basa en la elección de los propios migrantes de regresar a su país de origen, sobre una base temporal o permanente, y sin la ayuda de un organismo público" (Cassarino, 2008, p. 66) 2 .

Cassarino (2008) subraya que el carácter voluntario del retorno no siempre se corresponde con el deseo que acompaña esta decisión y, sugiere la importancia de considerar el análisis de la preparación del retorno.

En la caracterización de las formas en las que se presenta la inserción laboral de los retornados, la preparación del retorno resulta estratégica y se considera un proceso heterogéneo y definido por tres rasgos: i) El tiempo de permanencia en el lugar de destino; ii) las circunstancias, favorables o no, en la sociedad receptora y de origen, que impulsaron el evento del retorno, y iii) la capacidad de gestión del sujeto a partir de los recursos y capitales disponibles antes de la migración o los acumulados durante la experiencia migratoria (Cassarino, 2014). Así, la preparación del retorno requiere tiempo, empieza en el lugar de destino, y continúa en el proceso de adaptación en el lugar de origen.

En algunos estudios de migraciones internacionales contemporáneas se ha explorado la incidencia de las redes sociales establecidas entre las comunidades de inmigrantes. Portes (2012) señala su importancia en estrategias económicas y resalta dos rasgos: funcionan como microestructuras de apoyo creadas por los mismos migrantes y generan solidaridad en condiciones de incertidumbre. El enfoque de redes

2 En este estudio sólo se considera el retorno voluntario dado que el retorno forzado requiere de perspectivas conceptuales y enfoques metodológicos diferenciados que no abordamos en este análisis ni incluimos en el marco empírico de la investigación. 
sociales muestra la relación entre los motivos y las condiciones del retorno asociado con cadenas migratorias y redes sociales desde las que se ofrece información, asistencia, apoyo afectivo y material. Estas redes se consideran un capital social que dinamiza, impulsa, sostiene o condiciona el proceso migratorio (Herrera y Montoya, 2015; Tovar, L., Victoria, M., Tovar, J., Troncoso, G. y Laverde, F., 2018).

De igual manera, Rivera (2013) ha establecido que la mayor o menor incidencia en la reintegración social y laboral estará determinada por el lugar que ocupan los retornados en la red de relaciones. Así mismo, Schramm (2011) ha señalado que la calidad de los vínculos y la gestión de conflictos con las redes personales influyen en el reajuste de las expectativas del retorno, en particular en el nivel de satisfacción de necesidades afectivas, de subsistencia y de movilidad social. De allí la importancia que adquieren los procesos de interacción entre el sujeto y las diferentes redes: el contenido y la direccionalidad de los vínculos, la continuidad y la frecuencia de las interacciones sociales (Requena, 1989; 1991).

Con respecto a la perspectiva metodológica, este estudio acude al análisis de las trayectorias laborales y se inscribe en los fundamentos teóricos del enfoque biográfico retrospectivo entendido como "el recurso para penetrar, explorar y comprender la subjetividad, los sentidos y las representaciones de los individuos, sobre hechos, procesos y acontecimientos que interesa explorar y que forman parte de su historia personal" (Reséndiz, 2001). Siguiendo a Rivera (2012, p.,463) la unidad de análisis se establece como un "segmento específico de la experiencia de vida la cual se define a partir del evento biográfico".

El análisis de las trayectorias se fundamenta en la narración de los acontecimientos que conforman el recorrido laboral de las personas entrevistadas, considerando los momentos de reorientación o bifurcación biográfica, definidos por Bidart y Longo (2007) como eventos, a veces imprevisibles, que inciden en la reconducción de las trayectorias laborales presentando marcos de posibilidades o alternativas para elegir. Se consideró de suma importancia articular en la dimensión temporal de las trayectorias, los elementos estructurales presentes en el tiempo histórico, así como los aspectos personales y las representaciones que se desligan del tiempo biográfico: la edad, la posición dentro del hogar, el balance frente a las metas y la capacidad de agencia del sujeto.

En la selección de los casos, siguiendo a Rivera (2012), se partió de un muestreo teórico y a partir de los casos empíricos considerados 
se analizó la experiencia migratoria para establecer los rasgos característicos y proponer una tipología de emigrantes retornados, según el estatus laboral que define la inserción en el mercado de trabajo.

\section{TRAYECTORIAS LABORALES DE MIGRANTES CALIFICADOS RETORNADOS EN CALI}

El análisis de trayectorias laborales de mujeres y hombres colombianos retornados, representa un aporte importante en el propósito de comprender la heterogeneidad y la complejidad de los eventos, de los recorridos laborales y los cambios que reorientan y definen la posición en la estructura ocupacional de este grupo poblacional. De igual forma, desde la perspectiva de trayectorias laborales, resulta relevante interpretar el lugar que ocupa la experiencia migratoria y la capacidad de gestión de diferentes recursos disponibles cuando la persona "está sujeta a un marco de posibilidades definidas por las condiciones estructurales que ha enfrentado y que marcan su trayectoria de vida" (Bermúdez, 2014, p.,261).

El análisis de la migración de retorno de personas calificadas plantea la importancia de conceptualizar este proceso en referencia a la posibilidad de reorientar o establecer una bifurcación en su trayectoria laboral, más aún si se considera que las experiencias laborales en las sociedades contemporáneas están expuestas a un amplio margen de incertidumbre y riesgo social, que se inscriben en procesos marcados por continuidades y cambios (Roberti, 2012).

Las trayectorias laborales que se presentan a continuación constituyen experiencias de hombres y mujeres que emigraron a Estados Unidos o España con el propósito de acceder a oportunidades laborales o educativas; la migración internacional aparece como una estrategia de relocalización para contrarrestar el déficit de oportunidades laborales acordes a sus expectativas y necesidades. El análisis realizado ha permitido establecer tres tipos de orientaciones en el estatus laboral: i) retornados vinculados laboralmente como asalariados; ii) retornados constituidos como trabajadores independientes o pequeños empresarios y iii) retornados laboralmente inactivos. Cada uno de estos estatus laborales presenta cambios, rupturas o continuidades, tanto en el marco biográfico como en el estructural, constituyendo una trayectoria laboral, de carácter singular y contingente. 


\subsection{Asalariados: dilemas entre lo material y lo simbólico}

Las personas que emigraron principalmente durante la primera década del siglo XXI hacia España y retornaron por encontrarse desempleadas o en condiciones laborales precarias, constituyen el grupo que clasificamos en esta categoría. Se trata de hombres y mujeres entre los 29 y 52 años; con niveles de calificación media y superior (Diagrama 1). Los hombres, quienes tienen formación técnica, han conservado su desempeño laboral en la misma rama de actividad económica (construcción e industria), sosteniendo una trayectoria sectorial durante la migración (Hualde, Guadarrama y López, 2016).

Las mujeres profesionales estuvieron vinculadas en condición de asalariadas en el sector público antes de la migración. Para estas mujeres el inicio de la carrera profesional se ubica en el sector de servicios sociales con diferentes periodos de vinculación laboral. La migración representó un punto de giro en sus trayectorias laborales, ubicándolas en ocupaciones por debajo de su calificación durante su experiencia migratoria, con excepción de Ángela, quien se desempeñó en ocupaciones correspondientes con su formación profesional (Diagrama 1).

\section{Diagrama 1}

\section{TRAYECTORIAS LABORALES DE PERSONAS RETORNADOS ASALARIADOS}

\begin{tabular}{|c|c|c|c|c|c|c|c|c|c|c|c|c|c|c|c|c|c|c|c|c|c|c|c|}
\hline $\begin{array}{c}\text { Alio } \\
\text { Nadimiento }\end{array}$ & $\begin{array}{l}\text { Mujerhomitre } \\
\text { migrante } \\
\text { retormado }\end{array}$ & 另 & ఏ & $\$$ & 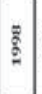 & $\begin{array}{ll}\hat{1} \\
\vdots \\
\vdots\end{array}$ & ఏ్రి & ถ్ & हू & हू & క్రి & ڤั & క్టి & ఫ్ & క్టి & ڤ్ & 总 & 高 & $\frac{\text { N }}{2}$ & $\frac{m}{8}$ & 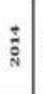 & $\frac{n}{2}$ & is \\
\hline 1965 & Antonio & $\mathbb{R}$ & & & $\Delta$ & & & & & & & & & 1 & $k$ & $X$ & $R$ & X & $\triangle 1$ & $\triangle 1$ & 41 & $x$ & 152 \\
\hline 1970 & Nancy & 8 & & X & $\triangle$ & $\gamma$ & & $X$ & $X$ & & $x$ & $E$ & $x$ & $\bar{X}$ & $\bar{X}$ & 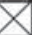 & $d$ & d & $\mathrm{R}$ & $\nabla$ & $\nabla$ & $\nabla$ & 45 \\
\hline 1970 & Angeth & 01 & $X$ & $\varepsilon$ & $d$ & $x$ & X & 2 & $X$ & & & $X$ & $\alpha$ & 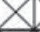 & & 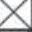 & $\Delta$ & $\triangle$ & $d$ & $R$ & $\triangle$ & $\triangle 1$ & 45 \\
\hline 1974 & Rubén & $X$ & & $x$ & X & $x$ & $m$ & 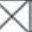 & 8 & $12 \times$ & 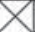 & $X$ & $X$ & $\times 1$ & 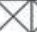 & $X$ & $E$ & $X$ & $T$ & X & $R$ & X1 & 42 \\
\hline 1987 & Lina & & & & & & & 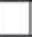 & & 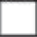 & 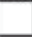 & 7 & . & 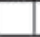 & & $T$ & $X$ & $X$ & $\Delta E$ & $\mathrm{R}$ & $\triangle 1$ & $\times 1$ & 29 \\
\hline & & & & & & & & & & & & & & & & & & & & & & ropia & \\
\hline
\end{tabular}

E: Emigración R: retorno d: desempleo

Permiso de residencia permanente o nacionalidad $\Delta$

Nacimiento de un hijo $\cong$

Fuente: elaboración propia a partir de las entrevistas realizadas en 2016. 
Los cambios en las condiciones laborales de este grupo de mujeres y hombres vinculados a lo largo de su vida como asalariados presentan diversas formas de precariedad laboral, condición que se acentúa en la reorientación laboral en el retorno, tanto para los hombres como para las mujeres, con algunas continuidades en relación con los empleos que tenían antes de emigrar. Un primer rasgo de contraste entre hombres y mujeres está en referencia a los motivos de emigración. Para las mujeres la migración se presenta en un momento en el que cuentan con estabilidad laboral y satisfacción con los ingresos y el cargo que desempeñan. Los hombres migran en un momento en el que están contratados a corto plazo en empresas privadas y reciben ingresos por debajo de sus expectativas. Entre los principales motivos para emigrar en las mujeres se identifica: la reagrupación familiar, el trámite de la nacionalidad en el país receptor o presiones externas. Factores de tipo relacional que disminuyeron el grado de autonomía para la elección de migrar, en tanto que mediaron acuerdos, compromisos y lealtades familiares. El siguiente fragmento ilustra las circunstancias familiares que incidieron en la migración de Nancy:

Cuando al final había logrado mi nombramiento en la Universidad se me presenta esto del viaje y todo, pues fue una situación bastante complicada, tomar la decisión fue muy difícil. () lo que mi esposo quería en el momento era tener a mi hija, pues, tener otra vez la unión familiar (Nancy, 45 años, Lic. Historia, retornada de España).

En contraste, para los hombres una de las principales razones que explica la emigración es la expectativa de acceder a oportunidades laborales y a mejores ingresos, dada la situación adversa en la que se encontraban en Cali. Al respecto Rubén comenta:

"Yo estaba estudiando y tenía trabajo, pero como te digo, la mentalidad de que allá iba a estar mejor (...) y se me dio la oportunidad y, listo, yo me voy (...), entonces, pues, cada mes mandaba lo de mis hijas y para el colegio de mi hermano, hasta que se graduó" (Rubén, 42 años, Técnico en metalurgia, retornado de España).

Aunque se trata de un grupo de migrantes con retorno voluntario, se expresa un bajo nivel de preparación o pocas condiciones para enfrentar la crisis económica que afectó el mercado laboral en España. Esta situación se expresa de manera importante en el déficit en capital económico que se tiene para afrontar el retorno. 
No obstante, se identifica que la experiencia laboral en la sociedad de destino permitió, principalmente a los hombres acumular otras formas de capital expresadas en diversas habilidades y conocimientos mediante prácticas de especialización y tecnificación, así como en el ejercicio de funciones de coordinación de equipos de trabajo y en el desempeño en ocupaciones calificadas fundamentadas en las experiencias laborales previas en Colombia o en procesos de formación en España. Así, realizar estudios en el país receptor, como sucede en el caso de Rubén, quien accede a formación técnica en metalurgia, representó una ventaja para vincularse a una empresa donde tuvo estabilidad laboral hasta que el sector de la construcción empezó a debilitarse. Por su parte, Antonio, técnico electricista, se mantuvo con un contrato de trabajo, durante dos años, con resultados sobresalientes en la ejecución de obras, pero con su salario drásticamente reducido. Pese al contexto y las circunstancias que inciden en la elección de regresar a Colombia, el capital cultural y escolar acumulado adquiere un valor importante para el migrante.

Para las mujeres la inserción laboral durante su permanencia en España se presenta, principalmente, en los servicios domésticos y en el comercio; tienen vínculos y jornadas de trabajo complementarias en estos sectores. En particular, los empleos en el sector comercial, como vendedoras o cajeras, permitieron a las mujeres migrantes calificadas y con permiso de residencia, contrarrestar las desventajas que representaba ocuparse en el servicio doméstico: inestabilidad, precariedad en los salarios, desprotección social y ubicación en un estatus laboral por debajo de su formación y calificación. En la experiencia de Nancy, se expresa el mejoramiento en las condiciones laborales, tras haber adquirido la formalización en su estatus migratorio y tras acceder a un empleo en un centro comercial. Al respecto, comenta:

Me hicieron el contrato, era la primera vez que tenía contrato y cotizaba a la seguridad social. Fue muy agradable el trabajo, conocía mucha gente, me tocaba atender, vender los productos, manejar caja, hacer inventarios (Nancy, 45 años, Lic. en Ciencias sociales, retornada de España).

En el caso de Ángela, quien es la única de este grupo que presenta una vinculación a largo plazo como profesional, enfatiza que este ascenso en la posición ocupacional en la sociedad receptora estuvo asociado con los estudios de posgrado que realizó a través del programa de asilo al que estaba vinculada. 
En síntesis, se puede señalar que las experiencias de inserción laboral de este grupo de migrantes durante su permanencia en la sociedad de destino conforman un reportorio de habilidades en el sentido expresado por Portes (2012), quien subraya la facilidad que tienen los migrantes con un alto nivel educativo para asimilar conocimientos y aprendizajes en su interacción en las sociedades de destino y, de esta forma, constituyen importantes capitales culturales y simbólicos.

Ante la crisis económica y las dificultades para sostener el vínculo laboral, el retorno al país de origen se constituye en una alternativa con la expectativa de vincularse al mercado laboral. Expectativa fundamentada en los recursos acumulados de tipo intangible, la experiencia laboral y la formación académica adquirida en la sociedad de destino que se perciben como ventajas relativas para dar continuidad a sus trayectorias laborales en el contexto del retorno.

En el contexto del retorno las mujeres presentan una reincorporación en los antiguos lugares de trabajo, en particular para Lina y Nancy, quienes a los seis meses de haber retornado se vincularon a las mismas empresas públicas en las que trabajaron antes de viajar a España. Se instalan en su trayectoria laboral interrumpida y recuperan el lugar social con el desempeño de un trabajo calificado en el país de origen. Por su parte, Ángela, se reincorpora laboralmente al mismo campo profesional en el que participaba antes de emigrar, el educativo. No obstante, las mujeres retornadas, específicamente quienes regresaron en edades cercanas a la etapa de consolidación de la vida laboral y productiva, enfrentan mayor desventaja en sus condiciones de trabajo respecto a su situación laboral antes de la migración y en relación a las condiciones materiales disponibles durante la experiencia migratoria. La inserción se presenta bajo contratos inestables, flexibles y con menos garantías de protección social. Para estas mujeres, el retorno se presenta acompañado de un escenario laboral incierto, menos satisfactorio y difícil de sobrellevar a la edad en la que lo hacen. Estas condiciones de precariedad laboral fortalecen su percepción de una experiencia migratoria "fallida" y se asocian con una respuesta social negativa frente al retorno. Así, el retorno representa empezar de nuevo y adaptarse a los cambios acontecidos durante la ausencia; se asocia con condiciones laborales flexibles e inciertas que limitan los proyectos a mediano y largo plazo, y condicionan las posibilidades de bienestar. Los casos de Ángela y Nancy resultan ilustrativos en tal sentido: 
$\mathrm{Al}$ retornar a Colombia, Nancy, tuvo que asumir un trabajo con múltiples funciones y el dominio de nuevas herramientas tecnológicas. Nancy tiene la presión de cumplir con un mayor número de responsabilidades y ha perdido un conjunto de derechos laborales, al ser ubicada como contratista de libre remoción. En el caso de Ángela, quien presenta el ciclo migratorio superior a 10 años, tras el retorno, ha estado vinculada en calidad de docente contratista y, de manera simultánea, como catedrática en una universidad y como profesora en una institución de educación secundaria. Esta doble contratación con estatus diferenciados en la calificación constituye una estrategia con el propósito de obtener los ingresos suficientes para los requerimientos básicos.

En el caso de los hombres, tras el retorno, se observa diferentes formas de precariedad laboral. Un primer aspecto tiene que ver con el diferencial en la remuneración que corresponde a los sectores productivos en los que se desempeñan los hombres. En Colombia la remuneración de la mano de obra que se ocupa en inmobiliarias para las remodelaciones, adecuaciones eléctricas o el sector de la soldadura no alcanza a equiparar los montos que percibían estas personas en España realizando funciones similares, lo que ha generado inconformidad e insatisfacción laboral. La experiencia de Antonio y de Rubén ilustra esta situación:

Antonio se vinculó, en calidad de empleado, en una microempresa realizando el mantenimiento de locaciones, durante cuatro años recibió una remuneración por debajo de sus expectativas, requiriendo complementar sus ingresos con actividades por cuenta propia para alcanzar a cubrir sus necesidades básicas. En el caso de Rubén, quien se encuentra vinculado con una empresa multinacional, afirma que, aunque recibe un salario adecuado, la intensidad en los horarios laborales le genera un desgaste físico y le restringe la posibilidad de disfrutar espacios de descanso con su red familiar y social.

Tanto para los hombres como para las mujeres retornadas que se vinculan como asalariadas está presente el riesgo de una inserción laboral tardía y la exposición a condiciones laborales caracterizadas por la inestabilidad y por salarios que no cumplen con sus expectativas y que limitan las posibilidades de planificar condiciones favorables para la vida en la vejez. Por otro lado, en sus trayectorias se identifica la necesidad de tener trabajos secundarios - y complementarios - como sucede en la experiencia de Antonio y de Ángela, sin que ello represente un incremento importante en los ingresos. 
Finalmente, resulta importante subrayar los dilemas que expresa este grupo de retornados frente a la posibilidad de iniciar nuevos proyectos migratorios o establecerse de manera indefinida en Colombia. Al respecto, se identifican expectativas de contraste entre hombres y mujeres, definidas en función de la vida familiar y, específicamente, por las formas de relacionamiento y dependencia que este grupo de retornados ha establecido con sus hijos.

Las mujeres consideran que volver a emigrar afectaría la estabilidad de los hijos, en particular el interés de garantizar la culminación de sus proyectos académicos, los cuales ya habían sido interrumpidos con el evento del retorno. Por lo tanto, la re-emigración para ellas no se presenta como una opción en el mediano plazo, aunque no lo descartan en el futuro.

Los hombres expresan que una nueva migración al mismo país de destino u otro constituye la principal alternativa para reorientar sus trayectorias laborales hacia proyectos que les permita revertir las condiciones de precariedad que hasta el momento han predominado en su ubicación como asalariados en Colombia. Esta opción migratoria está asociada a una mayor libertad en la movilidad en tanto sus proyectos migratorios se han caracterizado por ser individuales. Aunque en sus experiencias migratorias pasadas han mantenido un vínculo afectivo en la distancia con sus hijos, en esta etapa avanzada de su trayectoria vital han redefinido esta relación parental porque sus hijos han adquirido la mayoría de edad o se han establecido en hogares monoparentales, bajo el cuidado de la madre.

\subsection{Independientes o pequeños empresarios: escalando peldaños para quedarse}

Las personas retornadas que se ubican en estas posiciones ocupacionales iniciaron los primeros recorridos laborales desempeñándose como asalariados, esta posición ocupacional se presenta previo a la emigración o se constituye en el primer estatus laboral en la experiencia migratoria. Tras el retorno, las personas de este grupo reorientan sus trayectorias laborales optando por el trabajo independiente hasta establecerse como pequeños empresarios. Se trata de retornados con un alto nivel de heterogeneidad con respecto a la edad, el nivel escolar y el lugar de procedencia de la migración. Sus proyectos migratorios se distinguen por el marco 
temporal en que iniciaron y por los motivos que los definen (Diagrama 2).

\section{Diagrama 2}

\section{TRAYECTORIAS DE PERSONAS RETORNADAS INDEPENDIENTES O PEQUEÑOS EMPRESARIOS}

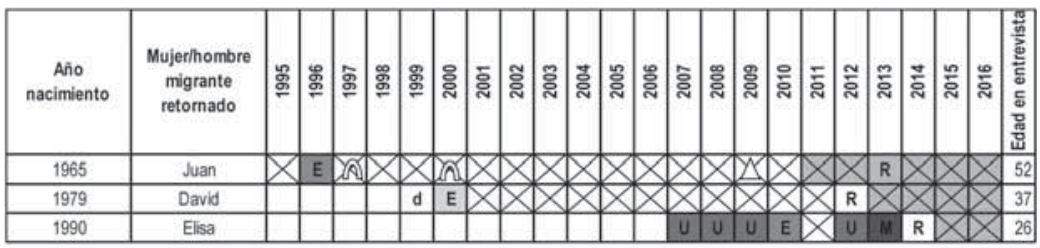

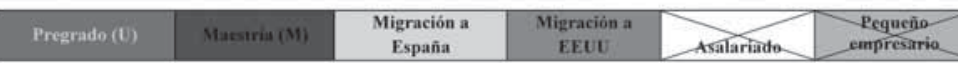

d: desempleo E: Emigración R: Retorno

Permiso de residencia permanente o nacionalidad $\Delta$

Nacimiento de un hijo $\curvearrowright$

Fuente: elaboración propia a partir de las entrevistas realizadas en 2016.

Para Juan, la migración hacia Estados Unidos en 1996 se presenta como un evento que altera el momento de transición de su carrera ocupacional, llevaba un corto periodo de haber instalado un negocio para constituirse como independiente, tras haber permanecido por cerca de 10 años como operario en empresas privadas en Cali. El principal motivo que define y justifica la migración de Juan y, posteriormente, la de su familia es la necesidad de sentirse seguro y alejado de lo que consideraba una ola de violencia y delincuencia en su ciudad.

El perfil de David se corresponde con la caracterización de emigrantes colombianos que conformaron el intensivo flujo hacia España, entre 2000 y 2005, por motivos laborales (Mejía, W., Ortiz, D., Puerta. C., Mena, J., y Díaz, M., 2009). David inicia su proyecto migratorio con la expectativa de acumular recursos económicos, propósito en el que sus familiares lo apoyaron financiando el viaje. En ese momento David se encontraba desempleado, con formación técnica en acabados en la construcción, el mismo sector en el que se desempeñaba su padre como independiente.

En el caso de Elisa, la migración internacional se presenta en un momento de su vida en el que intentaba reorientar la trayectoria 
educativa y de vida. El proyecto migratorio empezó como un viaje de aventura para encontrar oportunidades en un lugar distinto a Colombia y se fue configurando en una experiencia de múltiples cambios y transiciones a nivel educativo, profesional, residencial y familiar. Los fragmentos de su testimonio muestran los giros que se presentan a partir de la migración:

Me contactaron con unos norteamericanos y asiáticos (...). De los resultados del trabajo salió algo muy bonito que sirvió para la tesis de doctorado de uno de ellos (...) enviaron los documentos a la Universidad, en EEUU; allá preguntan por la persona que había hecho la parte de diseño. Enviaron mis datos y me pidieron todos los papeles. Esa Universidad me otorgó la entrevista, luego me dieron el permiso para trabajar; justo ahí fundé una revista con una persona de ese equipo que es arquitecto" (Elisa, 26 años, arquitecta, retornada de Estados Unidos).

Los trabajos desempeñados de más larga duración que distinguen a este grupo de retornados mientras permanecieron en Estados Unidos o en España estuvieron vinculados con su nivel educativo y con sus desempeños profesionales y ocupacionales que habían tenido en Colombia. En este grupo la inserción laboral se presenta en correspondencia con el grado de calificación y con el nivel de ingresos a los que tuvieron acceso durante el ciclo migratorio.

Elisa puede considerarse un caso atípico, en tanto que es la única migrante que en un corto plazo accede a oportunidades laborales de alta calificación, aunque bajo contratos temporales. No obstante, tras mantener su empleo en una universidad por un año, Elisa adquiere un visado estudiantil y, de esta manera, prolonga su proyecto migratorio en Estados Unidos con la intención de finalizar sus estudios de pregrado y continuar formación de posgrado. Esta trayectoria se sitúa en una línea de reorientación hacia un itinerario ideal (Hualde, et al., 2016), en el que la migrante logra conciliar aspiraciones y metas académicas con el posicionamiento como empleada profesional, en la sociedad de destino.

Para los hombres el periodo de vinculación laboral más largo ocurre en el país de destino, en donde permanecieron entre 12 y 16 años, constituyendo la etapa más representativa en la experiencia laboral acumulada, para especializarse en una profesión u oficio y acumular capital económico. En los primeros años de la experiencia migratoria Juan y David enfrentaron la desventaja de mantener 
un estatus migratorio irregular, y estaban condicionados a la multiactividad y sometidos a una alta intensificación en el trabajo para obtener mayor nivel de ingresos. Las posibilidades de ascenso en esta trayectoria laboral estuvieron delimitadas por dos aspectos: de un lado, el contexto económico del país receptor fue determinante para acceder a mejores salarios y, de otro lado, las estrategias personales basadas en el intercambio de recursos entre redes migratorias y relaciones sociales de tipo vertical resultaron importantes para tener mayor estabilidad y ocupar una mejor posición ocupacional. Las experiencias de Juan y David contrastan, en particular por las condiciones estructurales y por las dinámicas que reorientaron la economía de España después de 2008.

Así, Juan completó una trayectoria laboral de cerca de 10 años en una empresa de construcción americana desempeñándose como operario y con responsabilidades de coordinación de trabajadores. Cuando Juan decide retornar, lo hace bajo la consideración de haber acumulado recursos económicos suficientes para establecerse en Colombia, reagrupar su familia y consolidar su negocio. El siguiente fragmento ilustra al respecto:

En uno de mis viajes empecé a mirar locales con mi esposa () Las personas con las que me empecé a asesorar me dijeron iusted va a poner una vidriería en Cali, hay ciento y pico y usted le va a meter otra más? Tratando como de desanimarlo a uno, pero uno tiene que ser emprendedor y creer que, si se puede, entonces empezamos con el negocio antes de regresarme del todo y, ese pequeño negocio que arrancó hace 6 años, tiene 7 empleados. (Juan, 52 años, bachiller, retornado de Estados Unidos).

David, por su parte, presentó una inserción laboral inestable, caracterizada por el tránsito entre varias ramas de actividad (de servicios y de construcción), ubicándose en trabajos temporales, trabajos secundarios, es decir, presenta una trayectoria flexible e insegura, en la que prevaleció la ocupación como operario de construcción y los empleos secundarios correspondían al sector del turismo. En total, David completó 12 años en España y en el momento del retorno no contaba con ahorros ni ningún tipo de inversión en Colombia, tampoco obtuvo la nacionalidad. Regresó al país con unos preparativos mínimos y con la expectativa de ejercer la ocupación en la que había ganado experiencia en España, así narra su experiencia: 
Dije que si volvía era para quedarme. Primero hablé con papá, mi papá ya se iba a pensionar, él tenía un negocio de paneles y yeso (obra blanca) y quería que yo siguiera con el negocio. Entonces, es volver a construir una meta y arranqué otra vez. Prácticamente mi papá me ofreció toda la herramienta, eso sí, yo traía herramienta que me sería de utilidad acá (...). Cuando llegué el negocio de papá estaba muy acabado, me propuse levantarlo, han pasado tres años y, en este momento, contamos con diez empleados (David, 37 años, bachiller, retornado de España).

Las circunstancias en las que se presenta el retorno para estos hombres, los ubica en un momento de transiciones en diferentes ámbitos: laboral, familiar y residencial. La planificación del retorno, sea en un mínimo nivel o en forma más sistemática, constituye el marco de oportunidades para elegir alternativas y actuar en función del rol productivo que los migrantes consideraban posible asumir tras su llegada al lugar de origen. En tal sentido, tanto David como Juan hacen un balance sobre los recursos acumulados en la experiencia migratoria y la posibilidad de gestionarlos en el medio familiar y social. Específicamente, su equipaje lo constituía la experiencia laboral, las habilidades y la disponibilidad mayor o menor de ahorros. En complemento, estas personas encontraron condiciones familiares favorables para establecer alianzas o trabajo colaborativo en el desarrollo de una idea de negocio o en el fortalecimiento de una empresa familiar.

En el caso de Elisa, quien permaneció 4 años en Estados Unidos, el retorno representa una ruptura para la trayectoria ideal que estaba consolidando, es decir, el tipo de trayectoria definida por Hualde, et al.(2016, p. 209) como el recorrido laboral en el que hay consistencia entre el capital cultural y educativo acumulado, así como el conjunto de estrategias y esfuerzos individuales para alcanzar logros profesionales. Sin embargo, el hecho imprevisible que obliga a Elisa a regresar asociado con una problemática familiar, no le determinó un estado de fragilidad o pesimismo, por el contrario, Elisa empieza a implementar estrategias para dar un giro positivo a su nueva condición como retornada desempleada.

Antes de constituirse como independiente, Elisa se enfrenta a condicionamientos de tipo estructural que generaron tensión y limitaron la capacidad de gestionar distintos recursos. Primero, cuando intenta ejercer la arquitectura de forma independiente, a través de una oficina para la asesoría y ejecución de obras, tiene que enfrentar 
una temprana frustración de este proyecto. Este fracaso está asociado con el desajuste entre la oferta y la demanda de este servicio calificado en el contexto de retorno. En este mismo sentido, al intentar vincularse como empleada encuentra barreras asociadas con la sobre-calificación, enfrentándose a un periodo de desocupación. Finalmente, ante la presión de no contar con los recursos para sostener el hogar, Elisa, y su grupo familiar, impulsan un proyecto productivo que articula el repertorio de habilidades de la familia, constituyéndose en una alternativa para contrarrestar el desempleo. Los siguientes fragmentos de entrevista ilustran esta experiencia:

Fue muy difícil (...) mi hermanita en la universidad, no hay que comer, no está el sueldo de mi mamá. Y dije: mamá no nos podemos quedar quietas (...) eres diseñadora de modas ipor qué no hacemos algo? Tengo una plata para comprar unos materiales, me vine para Cali a conseguirlos y entonces ¿qué hacemos? Pues maletines mamita, hagamos maletines. Empezamos a hacerlos y la gente empezó a comprarnos. Abrieron una convocatoria (Cámara de Comercio) para una idea de negocio, chiquitica como de dos millones (...). Nos ganamos la convocatoria y nos dieron los dos millones de pesos en insumos (...). La empresa sigue, es nuestra empresa, ahora tenemos una operaria, ella hace los moldes, mi mamá organiza las cotizaciones, toda clase de cosas, yo le mando los materiales, me encargo de la publicidad. (Elisa, 26 años, arquitecta, retornada de Estados Unidos).

En síntesis, las personas retornadas que se integraron como independientes, lo hicieron a partir de la gestión de diferentes recursos simbólicos y materiales. En ese sentido reconocen la integración en la sociedad de origen en tanto que tienen satisfacción por el avance en las metas económicas, lo que les ha permitido acceder a condiciones de vida más estables comparadas con aquellas que tenían antes de la migración.

Los retornados que se establecieron como pequeños empresarios tras su regreso a Cali, comparten haber logrado articular el reportorio de habilidades con circunstancias contextuales como el apoyo y la participación familiar en el proceso de integración laboral.

En este tipo de inserción, factores asociados con rasgos personales y estrategias establecidas con redes familiares, tuvieron igual o mayor nivel de incidencia que los ahorros o bienes materiales de los que disponían los migrantes retornados para la integración sociolaboral. En tal sentido, la experiencia migratoria internacional y la 
gestión de diferentes recursos acumulados o generados durante el retorno representaron un aporte importante en la consolidación de este tipo de vinculación laboral.

\subsection{La inactividad al retorno: una etapa para disfrutar la vida y ser felices}

Un tercer tipo de trayectoria entre las personas retornadas se caracteriza por la inactividad laboral tras el retorno a Cali. Después de permanecer entre 12 a 14 años en Estados Unidos, las personas que se identificaron como inactivas, retornaron al completar el ciclo migratorio, alcanzando las metas propuestas en el proyecto migratorio (Diagrama 3).

Las experiencias de Hernán y de Gladis, quienes al momento del retorno superaban los 50 años de edad y se encontraban en tránsito hacia la etapa del ciclo de la vida familiar denominado: nido vacío ${ }^{3}$ (Quintero, 1997) ilustran este tipo de retorno. Ambos iniciaron su trayectoria laboral a principios de los años 90, con vinculaciones como asalariados en empresas públicas en Cali. Tras un largo período en esta vinculación, Hernán y Gladis tuvieron que enfrentarse a una situación de desempleo y a las demandas económicas de sostenimiento de sus hijos/as. La migración hacia Estados Unidos constituyó una alternativa para financiar la educación de sus hijos y ahorrar para el retiro laboral.

El segundo rasgo de esta trayectoria laboral lo constituye el acceso temprano al estatus migratorio legal en el lugar de destino. En un plazo de un año, Gladis y Hernán accedieron al permiso de residencia permanente a través de la gestión y apoyos de redes familiares y de amigos residentes en ese país. Este estatus migratorio se constituyó en un capital no sólo material sino simbólico que favoreció sus condiciones laborales: accedieron a contratos de trabajo con seguridad social, estabilidad e ingresos salariales que se correspondían con sus expectativas.

Así, no sólo la pertenencia a determinadas redes sociales sino la calidad de los vínculos, la reciprocidad y los contenidos (afecto,

3 Corresponde a la etapa del ciclo vital familiar en la que los hijos han alcanzado un nivel de autonomía e independencia y se proyectan a los sistemas externos. 
apoyo económico, nuevos contactos, cartas de recomendación, información jurídica, entre otros) fueron aspectos centrales para facilitar la integración social y laboral en la sociedad de destino. Se ha enfatizado en el poder de las redes en tanto que las redes fuertes y débiles constituyen medios de circulación de la información y de promoción del empleo, en medio de los nuevos procesos económicos y de la lógica de acumulación de capital (Pedone, 2003, p. 119). En segundo lugar, las capacidades personales que constituyen el conjunto de recursos internos del migrante para desenvolverse en el campo socio-laboral, tales como el nivel de escolaridad alcanzado, la experiencia laboral, el capital simbólico, influyen en el proceso de integración laboral (Bermúdez, 2010) con la posibilidad de acceder a mejores salarios y a posiciones ocupacionales más estables y satisfactorias para sostener el proyecto migratorio. Los siguientes fragmentos de entrevistas ilustran las circunstancias en las que se presenta la inserción laboral en el lugar de destino:

"Cuidar niños es un trabajo para el gringo muy importante y te va a pagar lo que en una oficina no pagan. En una oficina quincenal en esa época yo me ganaba 250 dólares, y pasé a ganar 360 en una semana, cuidando niños" (Gladis, 52 años, con formación superior incompleta, retornada de Estados Unidos).

Por mis condiciones, mis conocimientos técnicos, yo me fui desenvolviendo y cogí confianza de los americanos dueños de la compañia, ellos me dieron un buen sueldo, me dieron responsabilidades, entonces alli me sentí muy bien durante los doce años, era una compañía de instalación de equipos para aire acondicionado (Hernán, 67 años, con formación superior incompleta, retornado de Estados Unidos).

De allí que se puede sugerir que el aprovechamiento de beneficios asociados con el capital social y cultural, se expresa, posteriormente, en oportunidades económicas. En estos casos, representó el acceso a contratos laborales formales, mejores ingresos y valoración del desempeño ocupacional. En suma, estas condiciones laborales facilitaron la capacidad de ahorro, inversión en educación de los hijos, compra de bienes y favorecieron la preparación del retorno.

Con respecto al cambio en la trayectoria laboral de Hernán y Gladis asociados con la migración internacional; en ambos casos, se presenta una ruptura en el estatus otorgado por el tipo de trabajo calificado que se desempeñaba antes de la migración con respecto 
al trabajo de menor calificación en el que se vinculan durante su permanencia en Estados Unidos. Sin embargo, puede afirmarse que se trató de una ruptura positiva (Hualde et al. 2016). Ambos implementaron estrategias para revertir la precariedad o la exclusión del mercado laboral en la sociedad de destino: aprender el idioma, ampliar la red de relaciones, aplicar conocimientos técnicos y sobresalir por su rendimiento en la empresa, representó estabilidad laboral y mejores ingresos. En el diagrama 3, se ilustra el marco temporal $\mathrm{y}$ algunos eventos que definen este tipo de trayectoria laboral a lo largo del ciclo migratorio.

Diagrama 3

TRAYECTORIAS DE PERSONAS RETORNADAS INACTIVAS

\begin{tabular}{|c|c|c|c|c|c|c|c|c|c|c|c|c|c|c|c|c|c|c|c|c|c|c|c|c|}
\hline $\begin{array}{c}\text { Año de } \\
\text { nacimiento }\end{array}$ & $\begin{array}{l}\text { Mujer/hombre } \\
\text { migrante } \\
\text { retornado }\end{array}$ & $\stackrel{10}{g}$ & $\vdots$ & $\stackrel{\hat{g}}{ }$ & : & g & : & $\begin{array}{l}\tilde{o} \\
\text { N }\end{array}$ & : & 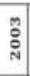 & : & $\begin{array}{l}\text { na } \\
\stackrel{0}{0} \\
\text { N. }\end{array}$ & : & $\hat{\vdots}$ & : & ڤ & $\frac{0}{0}$ & $\frac{2}{\mathrm{~S}}$ & $\frac{N}{\circ}$ & $\frac{\pi}{2}$ & $\frac{2}{5}$ & $\frac{n}{\mathrm{n}}$ & $\frac{0}{\mathrm{n}}$ & $\begin{array}{c}\text { Edad } \\
\text { entrevista }\end{array}$ \\
\hline 1950 & Hemin & & & & & & & & & & d & & & & & & & & & $X$ & $R$ & 1 & 1 & 67 \\
\hline 1964 & Gods & & & $d$ & & E & & & & & & & & & & & & $R$ & 1 & 1 & 1 & 1 & 1 & 52 \\
\hline
\end{tabular}

\begin{tabular}{|c|c|c|c|c|}
\hline $\begin{array}{c}\text { Migración a } \\
\text { Estados Unidos } \\
\text { (E) }\end{array}$ & $\begin{array}{c}\text { Retorno } \\
\text { (R) }\end{array}$ & EMHruEADo & $\begin{array}{c}\text { Desempleado } \\
\text { (d) }\end{array}$ & $\begin{array}{c}\text { Inactivo } \\
\text { (I) }\end{array}$ \\
\hline
\end{tabular}

E: Emigración

R: Retorno

Permiso de residencia permanente o nacionalidad $\Delta$

Nacimiento de un hijo $\cong$

Fuente: elaboración propia a partir de las entrevistas realizadas en 2016.

El tercer rasgo que caracteriza las trayectorias de los retornados inactivos tiene que ver con el proceso de preparación del retorno, en el cual la edad del migrante, el deseo de regresar y el balance favorable frente a las metas propuestas, fueron aspectos complementarios, y fueron el resultado de un plan familiar que garantizaría la permanencia definitiva en el lugar de origen. Así aparece registrado:

Mi venida la comencé a preparar desde que me fui. Todo el tiempo yo tenía claro que tenía que venirme, y trabajé, compré mi casa, un par de lotecitos que tengo ahí en Jamundi, reuní unos centavitos, alcancé lo de la pensión () entonces dije, no más reciba la pensión de los EEUU, regreso (Hernán, 67 años, con formación superior incompleta, retornado de Estados Unidos). 
Tomamos la decisión de regresar porque allá todo estaba prácticamente organizado, y habiamos visto que nuestros hijos estaban bien, tenían una profesión, y esa parte fue lo mejor, esa parte no tiene precio. (...) ya nosotros habiamos hecho lo que se podía hacer y pensamos ya como retornar a la casa. (Gladis, 52 años, con formación superior incompleta, retornada de Estados Unidos).

Finalmente, se señalan algunos aspectos subjetivos en el retorno en este tipo de trayectoria. Se identifica arraigo por el lugar de origen, así como vínculos familiares fuertes, que se expresa en el interés de invertir en bienes inmobiliarios sobre la base de establecerse en la misma ciudad; expresan satisfacción al evaluar que la experiencia migratoria les permitió circunstancias económicas mejores comparadas con la etapa previa al proyecto migratorio y les favoreció mejores condiciones para afrontar la vejez.

\section{REFLEXIONES FINALES}

El análisis que hemos realizado de la inserción laboral de migrantes internacionales retornados a Cali desde una perspectiva longitudinal, en el que hemos considerando las trayectorias laborales como un proceso continuo que abarca la experiencia acumulada previa a la migración, así como la migración misma, nos ha permitido una aproximación a este fenómeno emergente en el que se enfatiza la importancia de diferenciar factores estructurales y subjetivos en este proceso.

En primer lugar, es importante subrayar que el análisis de las trayectorias laborales de los migrantes retornados permitió establecer rasgos comunes y diferenciadores que definen tres tipos de estatus laboral en el momento del retorno: empleados asalariados, trabajadores independientes o pequeños empresarios y retornados que optan por la inactividad laboral. Estos tipos de estatus laboral en la etapa del retorno están asociados a cambios en la acumulación de diferentes capitales simbólicos, sociales y económicos gestionados de diversas formas según el lugar de destino.

De acuerdo a lo anterior, tanto en Estados Unidos como en España, el conjunto de trayectorias se reorientaron hacia vinculaciones laborales más satisfactorias comparadas con la etapa previa a la migración, permitiendo la ampliación de oportunidades económicas 
y la trasformación del capital simbólico a través del desempeño en trabajos calificados, sin embargo, es importante señalar que en el caso de quienes retornaron de España, en su mayoría bajo circunstancias de menor preparación en términos de disponibilidad de ahorros y capital económico acumulado, estuvieron expuestos a un escenario de imprevisibilidad para incorporarse al mercado laboral.

En ese contexto, para las personas vinculadas como asalariadas durante el retorno, las posibilidades de mejorar las condiciones laborales estuvieron limitadas pese a haber reconducido sus trayectorias en ocupaciones que desempeñaban antes de la migración, en tanto que las oportunidades de vinculaciones laborales con estabilidad fueron cada vez más escasas. Es preciso subrayar que los migrantes retornados con edades productivas tardías, debieron conformarse a estar contratados bajo regímenes de desprotección y flexibilidad laboral.

Por otro lado, la multiactividad y la doble contratación es un rasgo presente en trayectorias con diferentes niveles de calificación, y se ha establecido como una estrategia para contrarrestar riesgos asociados con la precariedad laboral: bajos salarios, contratos a término definido, el subempleo o la desocupación; asimismo, se observa que la multiactividad intensifica el trabajo sin generar los ingresos esperados. En ese orden, se puede sugerir que las condiciones laborales que caracterizan el estatus de asalariados en el lugar de origen dificultan el proceso de integración, en medio de circunstancias personales y familiares que imponen mayores demandas no solo de consumo material, sino de acceso a niveles de bienestar que tenían durante su permanencia en el lugar de destino y no encuentran en el retorno. En consecuencia, este tipo de trayectoria laboral es susceptible a presentar nuevas reorientaciones con base en la idea de emprender otros proyectos migratorios.

En contraste, las personas procedentes de Estados Unidos, en su mayoría, reunieron soportes económicos importantes para pasar a una etapa de transición de la vida laboral, ellos pudieron elegir entre retirarse del mercado de trabajo o establecer formas con mayor autonomía para ejecutar su trabajo, en todos los casos como pequeños empresarios. Tanto las personas que pasaron a ser inactivas como quienes reorientaron sus trayectorias hacia el estatus de independientes presentan mayores niveles de integración, y de esta forma se expresa el deseo y la posibilidad de cerrar el ciclo migratorio en tanto que se logró un mayor arraigo en la sociedad de origen y se cuenta con el fortalecimiento de sus relaciones familiares. 


\section{BILBIOGRAFIA}

Bermúdez, R. (2010). Migración calificada e integración en las sociedades de destino. Sociedad y Economía, (19), 135-150.

Bermúdez, R. (2014). Trayectorias laborales de mujeres migrantes calificadas por razones de estudio. Estudios Demográficos y Urbanos, 29 (2), 257-299.

Bidart, C., y Longo, E. (2007). Bifurcaciones biográficas y evolución de la relación con el trabajo. VIII Congreso Nacional de Estudios del Trabajo, Buenos Aires. Recuperado de: https://halshs.archives-ouvertes.fr/halshs-00490471/

Cassarino, J. P. (2008). Entender los vínculos entre migración de retorno y desarrollo. En: G. Pinyol (Ed.), La dimensión exterior de las políticas de inmigración en la Unión Europea. Fundación CIDOB (pp. 63-87). Recuperado de: https://www.academia.edu/828979/ JeanPierre_Cassarino_Entender_los_v\%C3\%ADnculos_entre_ migraci\%C3\%B3n_de_retorno_y_desarrollo

Cassarino, J. P. (2014). Bridging the policy gap between reintegration and development. En: Cassarino, J. (Ed.), Reintegration and development (1-17). Recuperado de: http://cadmus.eui.eu/handle/1814/30401

Castro, Y., y Mejia, W. (2012). Retorno de migrantes a la Comunidad Andina. Bogotá: Fundación Esperanza. Recuperado de: https:// redretornoycircularidad.files.wordpress.com/2015/07/mejc3aday-castro-2012.pdf

Durand, J., y Massey, D. (2003). Nuevo perfil. En J. Durand y D. Massey (Ed.), Clandestinos: Migración México-Estados Unidos en los albores del Siglo XXI. (pp. 11-43). Recuperado de: https://mmp. opr.princeton.edu/databases/pdf/Clandestinos.pdf

Herrera, M., y Montoya, E. (2015). Migración de retorno: una interpretación teórica y conceptual frente a las cifras de migrantes retornados de Estados Unidos a México. En E. Montoya y M. Nava (Coord.) Migración de Retorno en América Latina. Una visión interdisciplinaria. México: Universidad Autónoma de Silanoa.

Hualde, A., Guadamarra, R., y López, S. (2016). Precariedad laboral y trayectorias flexibles en México: un estudio comparativo de tres ocupaciones. Papers, 101, (2), 195-221. Recuperado de: http://papers.uab.cat/article/view/v101-n2-hualde-guadarramalopez/2188-pdf-es 
Hirai, S. (2013). Formas de regresar al terruño en el transnacionalismo: Apuntes teóricos sobre la migración de retorno. Alteridades, 23 (45), 95-105. Recuperado de: https://alteridades.izt.uam.mx/ index.php/Alte/article/view/718

Koolhaas, G. M. (2015). Migración internacional de retorno en Uruguay: magnitud, selectividad y reinserción laboral en tiempos de crisis económica internacional. (Serie Tesis de Maestría en Demografía y estudios de población, No 5). Universidad de la República. Montevideo. Recuperado de: cienciassociales.edu.uy/ wp-content/uploads/sites/6/2015/10/Tesis-Maestría-No5.pdf

Martínez, J., Cano, V., y Soffia, M. (2014). Tendencias y patrones de la migración latinoamericana y caribeña hacia 2010 y desafíos para una agenda regional. Serie Población y Desarrollo, $\mathrm{N}^{\circ}$ 109. Recuperado de: https://www.peacepalacelibrary.nl/ebooks/ files/395285372.pdf

Mejía, W., Ortiz, D., Puerta. C., Mena, J., y Díaz, M. (2009). Encuesta Nacional de Migraciones Internacionales y Remesas 2008-2009. Resultados generales. Recuperado de: https://www.humanas.org. co/archivos/InformeEncuesta.pdf

Nieto, C. (2012). Migración de retorno y capital humano. Universitas, (16), 53-67. Recuperado de: https://dialnet.unirioja.es/descarga/articulo/5968492.pdf

Pedone, C. (2003). "Tú siempre jalas a los tuyos". Cadenas y redes migratorias de las familias ecuatorianas hacia España. (Tesis de doctorado). Universidad de Barcelona, España. Recuperado de: http://www.tdx.cat/handle/10803/4956

Portes, A. (2012). Sociología económica de las migraciones internacionales. L. Chacón (Ed.). Barcelona: Anthropos; CIDOB.

Prieto, V. (2015). Recomendaciones de política para la inserción laboral de retornados en Colombia. Informe final: análisis de resultados y recomendaciones a partir del caso colombiano. Bogotá: OIM - Ministerio del Trabajo. Recuperado de https://cercomision.files.wordpress.com/2018/01/insercic3b3n-laboral-retornados.pdf

Prieto, V., Pellegrino, A., y Koolhaas, M. (2015). Intensidad y selectividad de la migración de retorno desde España y los Estados Unidos hacia América Latina. En: F. Lozano y J. Martínez (Eds.), Retorno en los procesos migratorios de América Latina. Conceptos, debates, evidencias. Serie Investigaciones No.16, Montevideo: Asociación Latinoamericana de Población (ALAP). 
Quintero, A. (1997). Trabajo social y procesos familiares. Argentina: Lumen Hvmanitas.

Ramírez, G. T., y Lozano F. (2015). Reinserción laboral de los migrantes calificados de retorno de los Estados Unidos a México: ¿ganancia o desperdicio de talentos? En: F. Lozano y J. Martínez (Eds.). Retorno en los procesos migratorios de América Latina. Conceptos, debates, evidencias. Serie Investigaciones No.16,Montevideo: Asociación Latinoamericana de Población (ALAP).

Reséndiz. R. (2001). Biografía: proceso y nudos teórico-metodológicos. En: M. Tarrés (Coord.) Observar, escuchar y comprender. Sobre la tradición cualitativa en la investigación social. México: CLACSO - El Colegio de México.

Requena, F. (1989). El concepto de red social. Revista española de investigaciones sociológicas, (48), 137-157. Recuperado de: https:// dialnet.unirioja.es/servlet/articulo?codigo $=249260$

Requena, F. (1991). Redes sociales y mercado de trabajo. Elementos para una teoría del capital relacional. Madrid: Centro de Investigaciones Sociológicas.

Rivera, L. (2012). Las trayectorias en los estudios de migración. Una herramienta para el análisis longitudinal cualitativo. En M. Ariza., y L., Velasco, (Coords.). Métodos cualitativos y su aplicación empírica. Por los caminos de la investigación sobre migración internacional. México: Universidad Nacional Autónoma de México y El Colegio de la Frontera Norte, pp. 455-494.

Rivera, L. (2013). Migración de retorno y experiencias de reinserción en la zona metropolitana de la ciudad de México. Revista Interdisciplinaria de Movilidad Humana, 21 (41), 55-76. Recuperado de: http://www.scielo.br/pdf/remhu/v21n41/04.pdf

Roberti, E. (2012). El enfoque biográfico en el análisis social: claves para un estudio de los aspectos teórico-metodológicos de las trayectorias laborales. Revista Colombiana de Sociología, 35(1), 127-149. Recuperado de: https://revistas.unal.edu.co/index.php/ recs/article/view/31341/39585

Shramm, C. (2011). Retorno y reinserción de migrantes ecuatorianos. La importancia de las redes sociales transnacionales. En: CIDOB, núm. 93-94, pp. 241-260.

Tovar, L., y Victoria, M. (2015) "Migrantes de retorno y emprendedores en Colombia”. En E. Montoya y M. Nava (Coords.) Migración de Retorno en América Latina: Una visión interdisciplinaria. México: Universidad Autónoma de Silanoa. 
Tovar, L., Victoria, M., Tovar, J., Troncoso, G., y Laverde, F. (2018). Factores asociados a la probabilidad de emprendimiento en migrantes, Migraciones Internacionales, Vol. 9, (3), 169-192.

Valenzuela, B., y Medina A. (2015). Jóvenes migrantes de retorno e incorporación al mercado de trabajo. El caso de los profesores de inglés en Sinaloa. En E. Montoya y M. Nava (Coords.) Migración de Retorno en América Latina. Una visión interdisciplinaria. México: Universidad Autónoma de Silanoa. 